\title{
Pellet Injuries to the Orbit
}

\author{
Jonathan F.B. Goodfellow Richard H. Caesar \\ Cheltenham General Hospital, Cheltenham, UK
}

We read the recently published article by Şahap Kükner et al. [1] with interest, as we have also managed a patient with an intraorbital pellet injury. However, we feel it may be of interest to highlight that not all patients are destined to have such a poor visual prognosis as described in their study.

Our patient presented to the accident and emergency department after being accidentally shot from close range with a .22 calibre air rifle. The pellet entry site was clearly visible (fig. 1) and an X-ray demonstrated the presence of an intraorbital pellet. However, there was no evidence of ocular penetration and the patient had a visual acuity of $6 / 6$ with a full range of extraocular muscle movements. A CT scan (fig. 2) showed the pellet lodged intracon- ally adjacent to the optic nerve and we presume the spinning rifle pellet either spiralled around the globe after entering the orbital tissues or hit the orbital wall and was deflected centrally. The patient was managed with a course of prophylactic antibiotics and the foreign body was left in situ. He remained completely asymptomatic at follow-up.

Our case underlines that if patients are asymptomatic and a non-organic foreign body is located posteriorly in the orbit, it is advisable to leave the foreign body in situ. It also serves as a reminder that some patients may maintain excellent vision following orbital pellet injuries and that the best management plan may be 'masterful inactivity'.

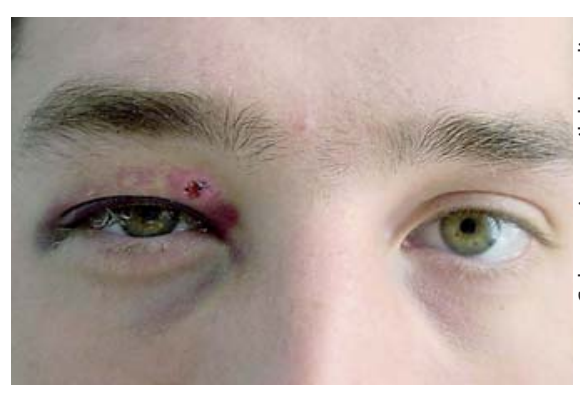

Fig. 1. Pellet entry site.
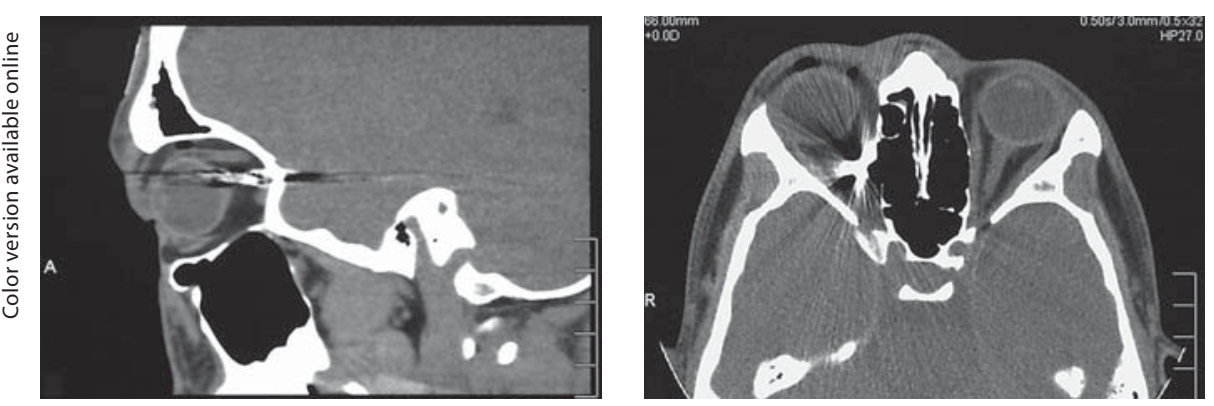

Fig. 2. CT scans showing the pellet lodged intraconally adjacent to the optic nerve.

\section{Reference}

1 Şahap Kükner A, Yilmaz T, Çelebi S, et al: Characteristics of pellet injuries to the orbit. Ophthalmologica 2009;223:390-395.

\section{KARGER}

Fax +41613061234 E-Mail karger@karger.ch www.karger.com

\section{(C) 2010 S. Karger AG, Basel \\ 0030-3755/10/2244-0265\$26.00/0}

Accessible online at:

www.karger.com/oph
Jonathan Goodfellow

Cheltenham General Hospital

Sandford Rd, Cheltenham, GL53 7AN (UK)

Tel. +44 7968942 201, Fax +448454222585

E-Mail jonathangoodfellow@ hotmail.com 